\title{
Investigation into Some Design Aspects of Ballasted Railway Track Foundations using Numerical Modelling
}

\author{
Md. Abu Sayeed, Mohamed A. Shahin \\ Department of Civil Engineering, Curtin University \\ Perth, WA, Australia \\ sayeed.ce00@yahoo.com
}

\begin{abstract}
Railways have become the most popular means of public transportation in many countries around the world. Therefore, an investigation into the impact of design parameters affecting the overall behaviour of railway track foundations under train dynamic loading is necessary for optimum and reliable design. Railway track foundations consist of a graded layer of granular media of ballast and subballast, which is laid on a naturally deposited subgrade soil. Most available methods for design of ballasted railway track foundations assume linear elastic behaviour for track geomaterials. However, the resilient behaviour of track geomaterials, especially the ballast layer, is mostly non-linear and may incur plasticity, depending on the level of applied stress. In this paper, a sophisticated three-dimensional finite element modelling is developed to investigate the track response subjected to train moving loads, by considering actual characteristics of track geomaterials including non-linearity and plasticity. The results are compared with the simpler elastic modelling response, and the practical implications are discussed.
\end{abstract}

Keywords: Numerical Modelling, Ballasted Railway Track, Effect of Ballast Nonlinearity, Effect of Subgrade Nonlinearity.

\section{Introduction}

The design of ballasted railway track foundations requires an accurate estimation of the thickness of granular layer (i.e. combined thickness of ballast and sub-ballast), so that it can provide an adequate protection against any possible track failure that might be caused by the repeated dynamic action of trains. The basis for design of track foundations used by most available methods is to calculate the minimum granular layer thickness that allows the transmission of imposed train loads at a tolerable stress on top of the subgrade layer. This means that a reliable estimation of the subgrade stress caused by train moving loads is a key element in the calculation of the granular layer thickness.

Several empirical and simplified theoretical methods have been proposed in the literature to calculate the granular layer thickness. These include the American Railway Engineering Association (AREA) manual [1]; Canadian Modified Method suggested by Raymond [2]; Japanese National Railways developed by Okabe [3]; British Rail method proposed by Heath, et al. [4]; UIC 719 R method offered by the International Union of Railways [5], and Li-Selig's method developed by Li and Selig $[6,7]$. These methods are based on stress analysis under oversimplified loading conditions, using static loading that cannot fully capture the dynamic impact of train moving loads, which is a serious shortcoming. However, when a train runs along a track, the ballast and soil elements become subjected to complex loading condition, including the principal stress rotation $[8,9]$. Accordingly, the train moving loads (i.e. cyclic loading with principal stress rotation) may affect the material stiffness and degree of cumulative plastic strain [10-12]. Moreover, most of the current design methods assume linear elastic behavior for geomaterials, which are generally nonlinear in nature and may incur plasticity, especially for the ballast layer nature [13]. Most methods also ignore the deformation of the granular ballast layer.

In this paper, the dynamic response of track-ground system subjected to train moving loads was investigated for some design aspects of ballasted railway track foundations, including the validity of the simpler linear elastic behaviour of track geo-materials compared to the more realistic nonlinear elastic and elastoplastic simulations. The current study is carried out using an advanced three-dimensional (3D) finite element (FE) numerical model that was previously developed by the authors $[14,15]$ and validated against field measurements data. 


\section{Numerical Modelling Approach}

The 3D FE model performed in the current study is depicted in Figure 1, using the commercial software package Midas-GTS [16]. The track dimensions considered were $80 \mathrm{~m}$ long, $36 \mathrm{~m}$ wide and $7.5 \mathrm{~m}$ high. The rail was modelled using one-dimensional (1D) I-beam section running across the track length. A UIC-60 section was assumed for the rail, which was fixed to the sleepers by rail pads characterized by an elastic link (spring-like) element of stiffness equal to $100 \mathrm{MN} / \mathrm{m}$. All other track components (i.e. sleeper, ballast and subgrade) were characterized using 3D solid elements. A total of 133 sleepers were placed along the rail at spacing of $0.6 \mathrm{~m}$.
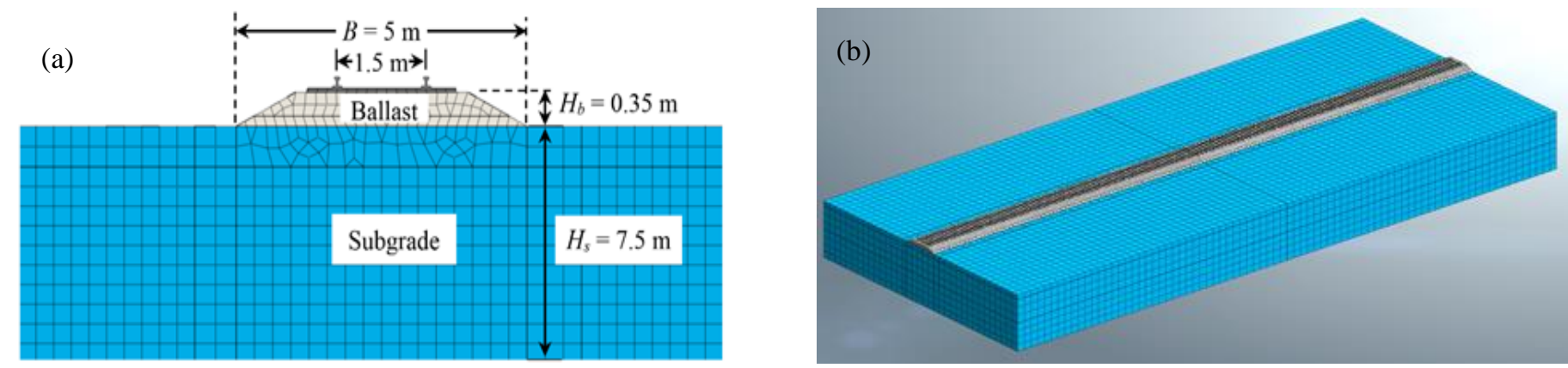

Fig. 1: FE model of the track-ground system: (a) cross-section of the track; (b) 3D view of the FE model.

In the FE dynamic analyses, the finite element size, model boundaries and time step have to be selected carefully to ensure the accuracy of the results [17]. In general, the element size of the FE model is usually estimated based on the smallest wave-length that allows the high-frequency motion to be simulated correctly. Accordingly, the sizes of the 3D FE model components used in the current study were taken as: $0.167 \times 0.137 \times 0.2 \mathrm{~m}, 0.2 \times 0.2 \times 0.2 \mathrm{~m}$, and $0.6 \times 0.6 \times 0.6 \mathrm{~m}$ for the sleepers, ballast and subgrade, respectively. Hence, the track FE mesh was consisted of 700,200 nodes and 115,000 elements. The vertical boundaries of the FE model were connected to viscous dampers to absorb the incident $S$ - and $P$ waves, and to represent infinite boundary conditions $[18,19]$. The nodes at the bottom boundary were fixed in every direction to simulate bedrock. The material damping of the FE model was characterized by the mass and stiffness proportional coefficients, normally referred to as the Rayleigh damping, which is commonly used in the dynamic analyses.

The train geometry and standard axle loads used in the FE model were selected to be for the X-2000 HST [20], as shown in Figure 2. The train moving loads were modelled in accordance with Araújo [21] in which the rail FE nodes, which are rigidly connected to the sleepers via pads, were subjected to a wheel load (denoted as loading nodes) whose value changes in time (note that the spacing between any two loading nodes is $0.6 \mathrm{~m}$ ). As schematically shown in Figure 3 , the train moving loads can be thought of as triangular pulses distributed among three nodes. The wheel load, $F$, at one certain loading node, $N+1$, increases once the wheel leaves node $N$, reaching a peak value when the wheel is directly above node $N+1$, then finally decreasing back to zero when the wheel reaches the next node $N+2$. As a result, the triangular pulse moves from one node to another by a time interval equal to the spacing between the loading nodes divided by the speed, $C$, of the moving train. In this fashion, a series of train wheels was considered to be moving along the track. During simulation of the train moving loads, the time step was selected based on the well-known Courant-Friedrichs-Lewy condition [17]. All FE analyses were performed in the time domain, which is more natural to reproduce the transient phenomenon of wave propagation [22]. 


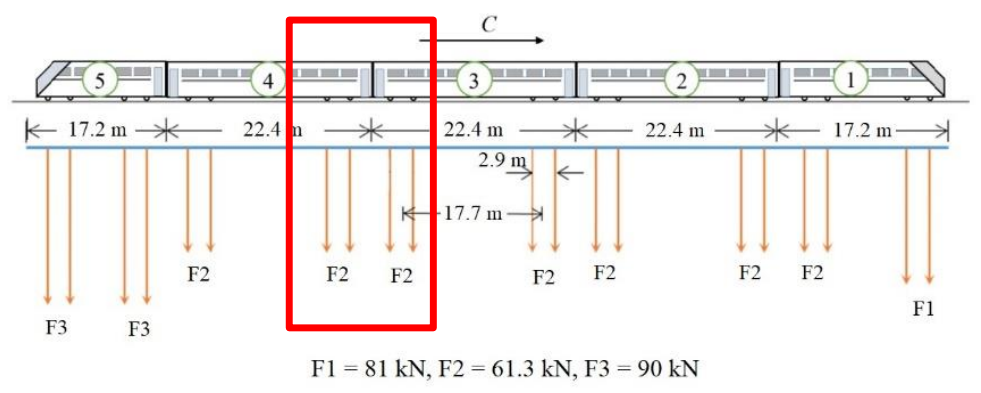

Fig. 2: Geometry and axle load of the X-2000 HST [20].

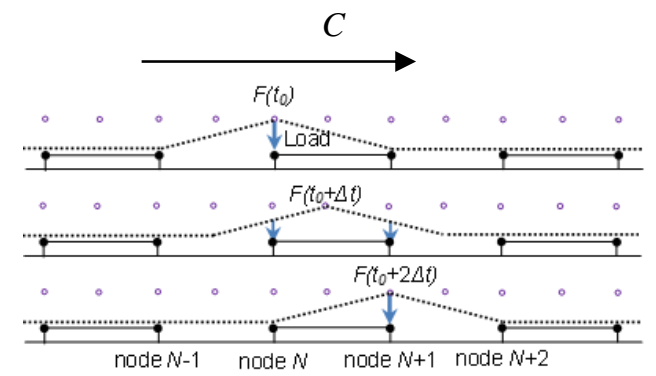

Fig. 3: Simulation of the moving loads [21].

\section{Effect of Ballast nonlinearity and Plasticity}

As mentioned earlier, the resilient behaviour of track geomaterials is usually assumed to be linear elastic, although these geomaterials are mostly non-linear and may incur plasticity, depending mainly on the applied stress level. Elastic modelling can be used to estimate the behavior of materials within a small strain level, but it is incapable of predicting the material behavior for stresses that exceed the yield limit or at higher strain. Consequently, use of linear elastic geomaterials might not appropriate and can lead to misleading results [23]. In this section, the effect of nonlinearity and plasticity of ballast on the track dynamic response was investigated in terms of the time history of stress and deformation, for locations where two consecutive bogies of the X-2000 HST are passing.

The impact of ballast elastic nonlinearity and plasticity on the stress and deformation behavior of the track was investigated using three different constitutive models. This includes a linear elastic (LE) model; hyperbolic Duncan-Chang (DC) non-linear elastic (NLE) model [24]; and an elastoplastic Mohr-Coulomb (MC) model. The rail, sleepers and subgrade were modelled as linear elastic materials. The linear elastic properties of ballast and other track materials are given in Table 1, whereas the ballast plastic and nonlinear elastic properties are given in Table 2. The locations of the selected elements under analysis are shown in Figure 4.

Table 1: Linear elastic properties of track materials.

\begin{tabular}{|l|l|l|l|l|}
\hline $\begin{array}{l}\text { Material } \\
\text { type }\end{array}$ & $\begin{array}{l}\text { Dynamic Young's } \\
\text { modulus, } E \\
(\mathrm{MPa})\end{array}$ & $\begin{array}{l}\text { Poisson's } \\
\text { ration, } v\end{array}$ & $\begin{array}{l}\text { Unit weight, } \\
\gamma \\
\left(\mathrm{kN} / \mathrm{m}^{3}\right)\end{array}$ & Damping, $\boldsymbol{\xi}$ \\
\hline Rail & 210000 & 0.30 & 76.50 & 0.03 \\
\hline Sleeper & 30000 & 0.20 & 20.15 & 0.03 \\
\hline Ballast & 162 & 0.30 & 18.64 & 0.03 \\
\hline Subgrade & 43.5 & 0.38 & 17.57 & 0.03 \\
\hline
\end{tabular}


Table 2: Plastic and nonlinear elastic properties of ballast.

\begin{tabular}{|l|l|l|l|l|l|}
\hline Material & $\begin{array}{l}\text { Cohesion, } c \\
\mathrm{kPa})\end{array}$ & $\begin{array}{l}\text { Friction } \\
\text { angle } \\
\phi^{\mathrm{o}}\end{array}$ & $\begin{array}{l}\text { Initial } \\
\text { loading } \\
\text { modulus, } K\end{array}$ & $\begin{array}{l}\text { Modulus } \\
\text { exponent, } n\end{array}$ & $\begin{array}{l}\text { Failure ration, } \\
R_{f}\end{array}$ \\
\hline Ballast & 0 & 53 & 1600 & 0.08 & 0.72 \\
\hline
\end{tabular}

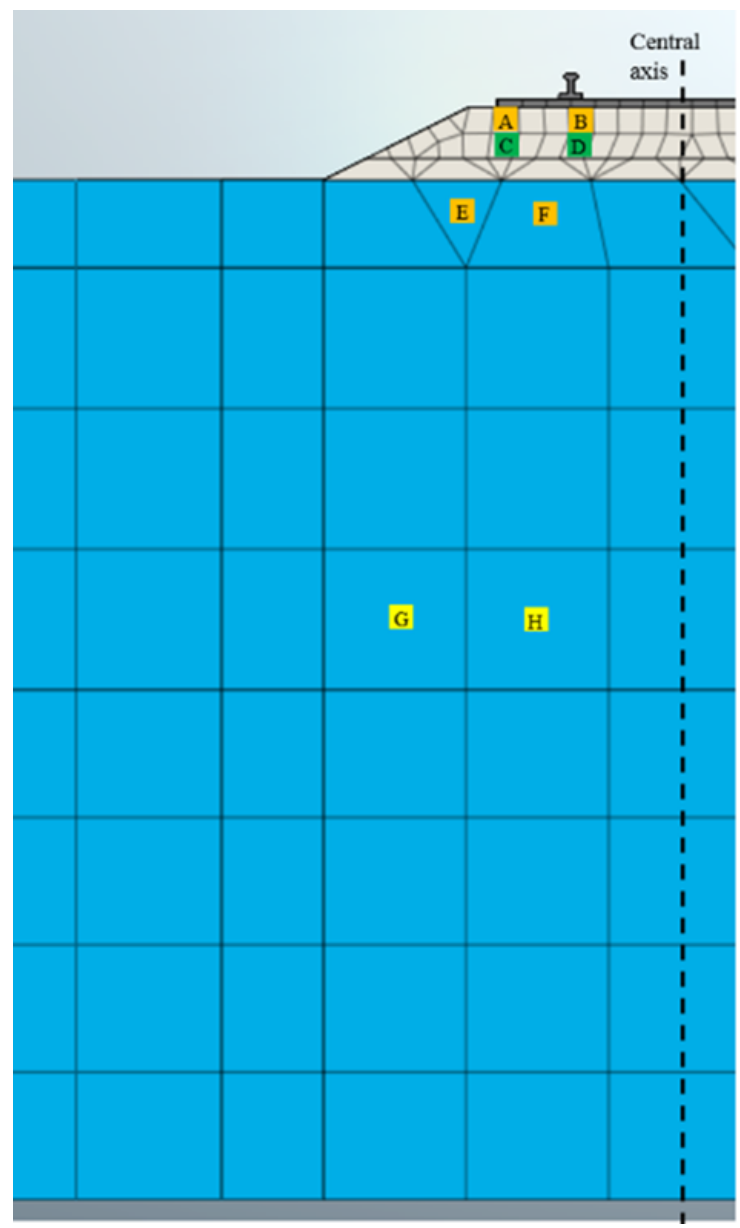

Fig. 4: Location of the selected elements under analysis.

Figure 5 compares the time history of vertical deflections at Points A and B (see Figure 4) obtained using different ballast constitutive models. It can be seen that, in general, the elastoplastic MC model resulted in slightly higher vertical deflections than those of both the linear elastic and non-linear elastic models. Similarly, Figures 6 and 7 show the time history of vertical stress $\left(\sigma_{z}\right)$ and deviatoric stress $(q)$ at Points A to D (see Figure 4), considering different ballast constitutive models. It can be seen that at some locations, the MC model gives slightly higher vertical and deviatoric stresses than the other two elastic models. This is attributed to the different load transfer from the sleepers to the ballast layer achieved by the different constitutive models. 
Time (s)

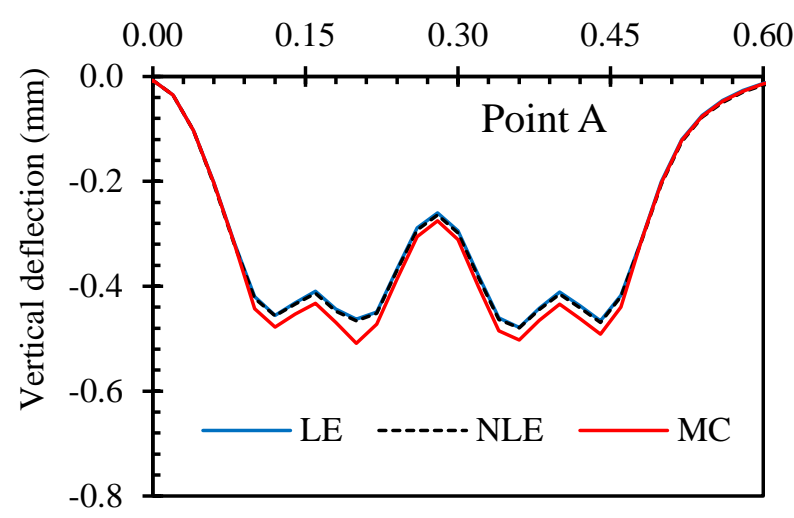

Time (s)

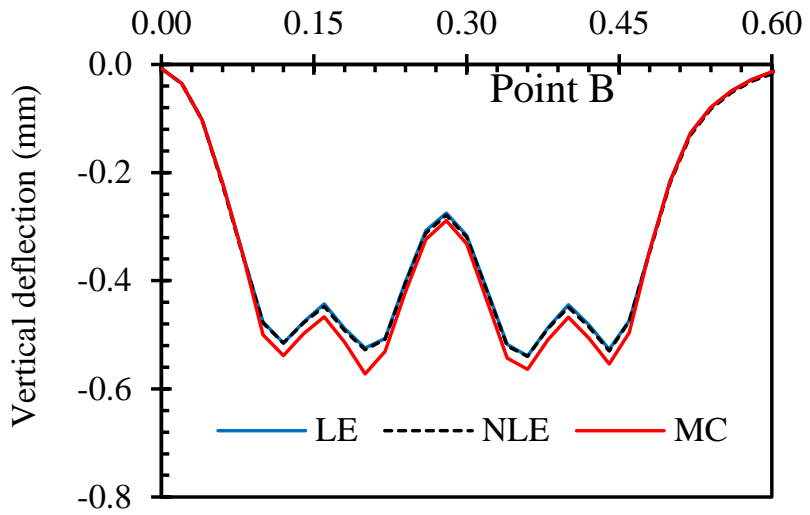

Fig. 5: Time history of vertical deflection at Points A and B considering different ballast constitutive models.

Time (s)

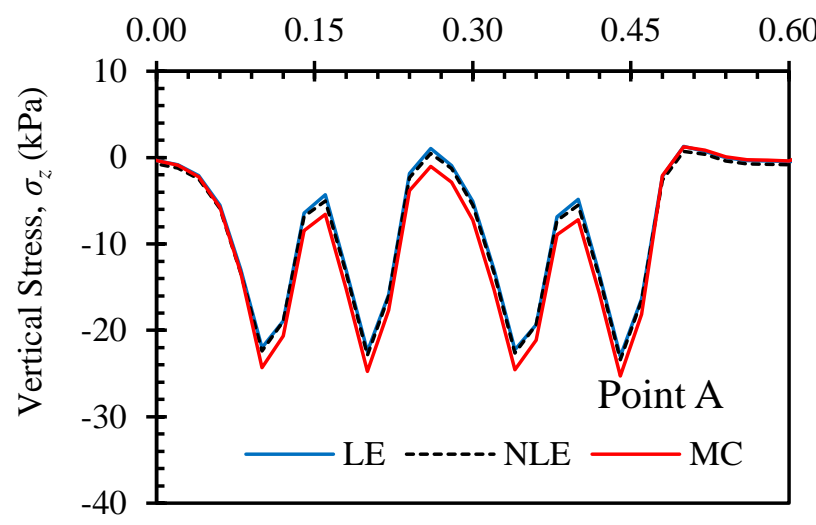

Time (s)

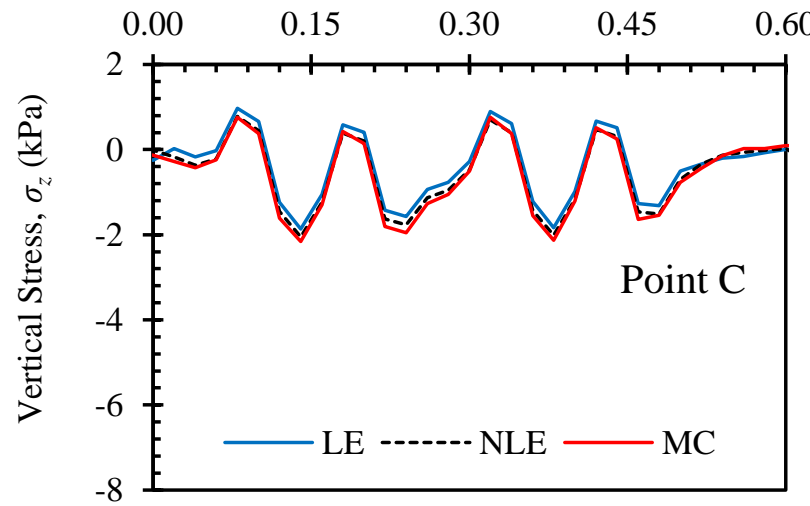

Time (s)

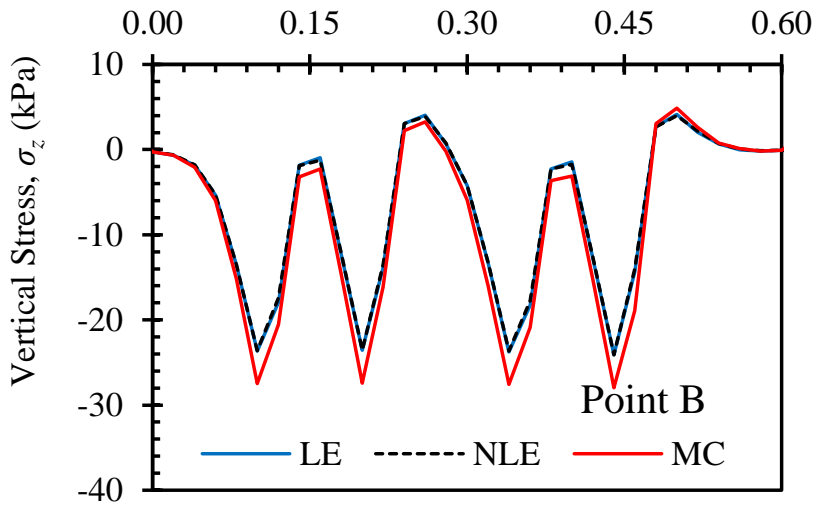

Time (s)

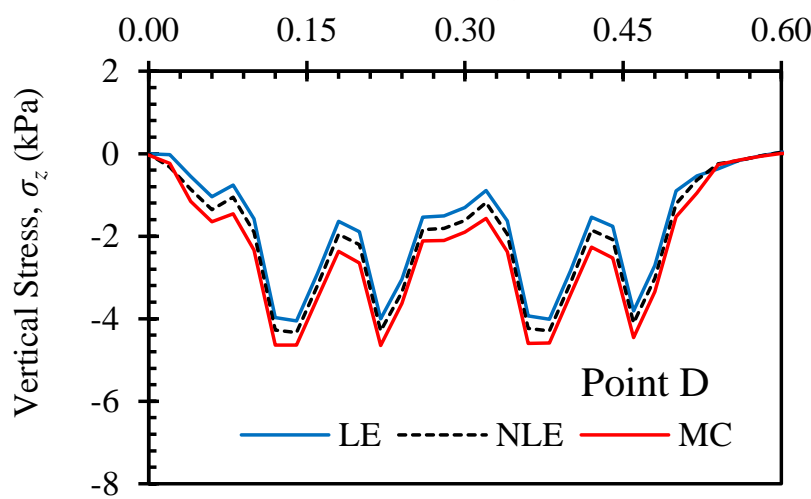

Fig. 6: Time history of vertical stress at Points A to D considering different ballast constitutive models. 
Time (s)
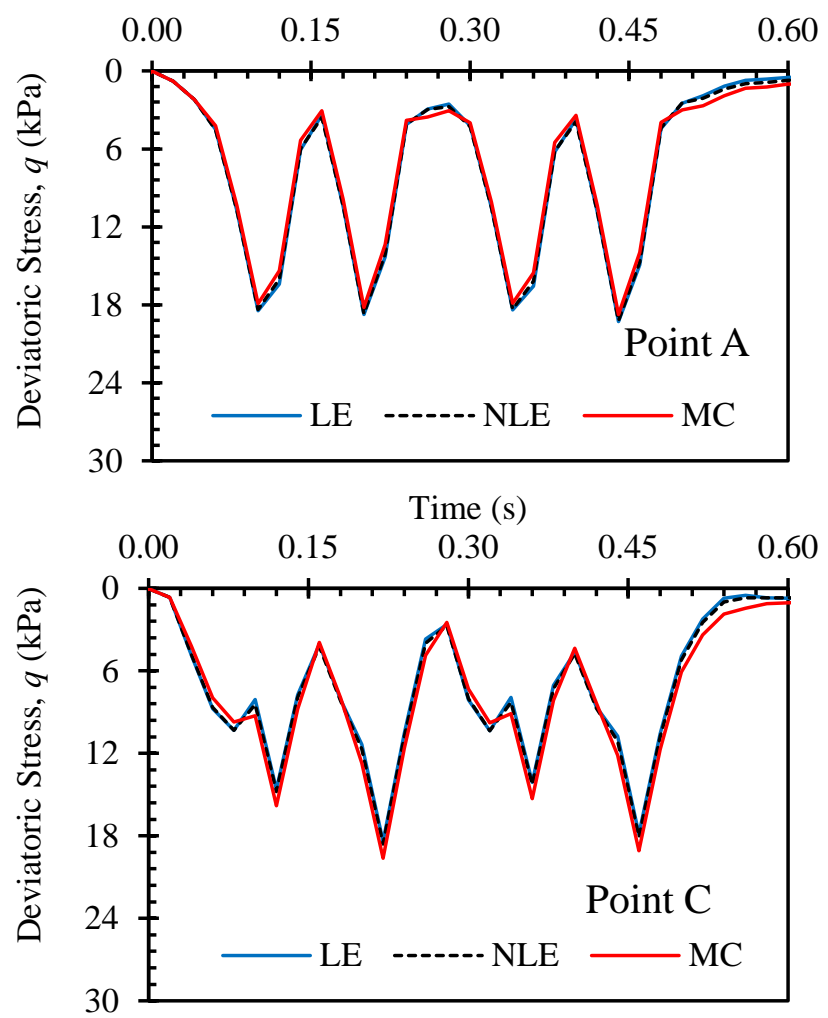

Time (s)

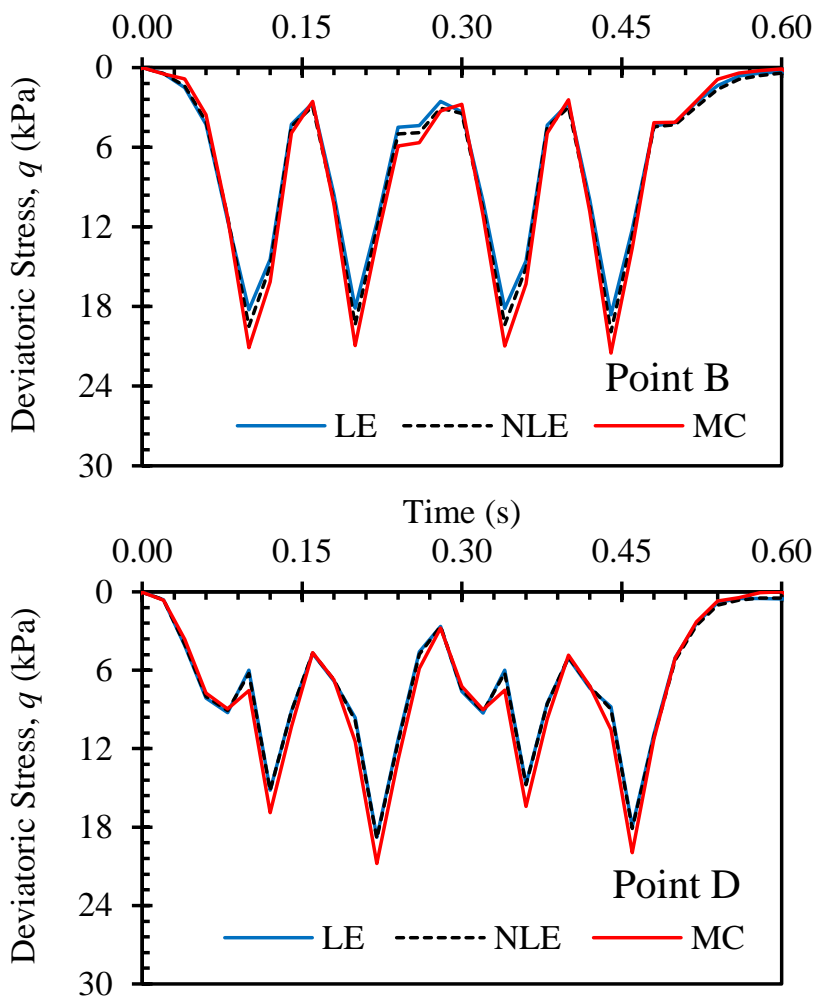

Fig. 7: Time history of deviatoric stress at Points A to D considering different ballast constitutive models.

\section{Effect of Subgrade Nonlinearity and Plasticity}

The impact of elastic nonlinearity and plasticity of the subgrade soil on the dynamic response of track was also investigated by simulating the subgrade soil using three different constitutive models (i.e. LE, NLE and MC). The rail and sleepers were modelled as linear elastic materials, whereas the ballast was modelled as elastoplastic Mohr-Coulomb material, which represents more actual characteristics for behavior of track granular media. The elastic properties of all track materials are previously given in Table 1, whereas the plastic and nonlinear properties of ballast and subgrade are summarized in Table 3.

Table 3: Plastic and nonlinear elastic properties of ballast and subgrade.

\begin{tabular}{|l|l|l|l|l|l|}
\hline Material & $\begin{array}{l}\text { Cohesion } \\
\mathrm{kPa})\end{array}$ & $\begin{array}{l}c, \text { Friction } \\
\text { angle, } \\
\phi^{\mathrm{o}}\end{array}$ & $\begin{array}{l}\text { Initial } \\
\text { loading } \\
\text { modulus, } K\end{array}$ & $\begin{array}{l}\text { Modulus } \\
\text { exponent, } n\end{array}$ & $\begin{array}{l}\text { Failure } \\
\text { ration, } \\
R_{f}\end{array}$ \\
\hline Ballast & 0 & 53 & - & - & - \\
\hline Subgrade & 124.5 & 6 & 430 & 0.10 & 0.93 \\
\hline
\end{tabular}

Figure 8 shows the time history of vertical deflections for Points A and B (see Figure 4) considering the three different constitutive models of subgrade soil. The results show that the subgrade nonlinear model resulted in slightly higher vertical deflections than those obtained from both the linear and elastoplastic models. As found by Sayeed and Shahin [15], the consideration of linear elastic and nonlinear elastic behaviour of geomaterials do not yield a significant variation in terms of the vertical sleeper deflections, particularly in case of stiff subgrade. So, it can be 
concluded that the linear elastic behaviour of subgrade can yield reasonable estimations of the overall behaviour of the track.
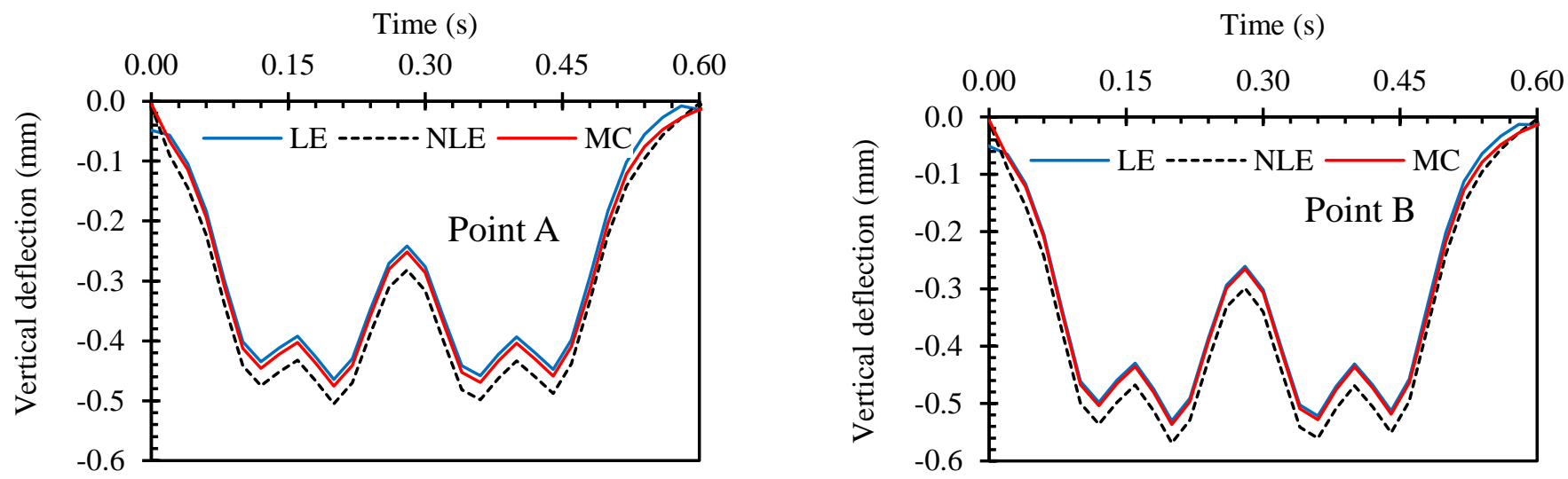

Fig. 8: Time history of vertical deflection at Points A and B considering different subgrade constitutive models.

Similarly, Figures 9 and 10 compare the time history of vertical stress $\left(\sigma_{z}\right)$ and deviatoric stress $(q)$ obtained using different subgrade constitutive models at Points $\mathrm{E}$ to $\mathrm{H}$ designated in Figure 4. It can be seen that the time history of vertical and deviatoric stresses are almost identical at all subgrade locations under analysis.
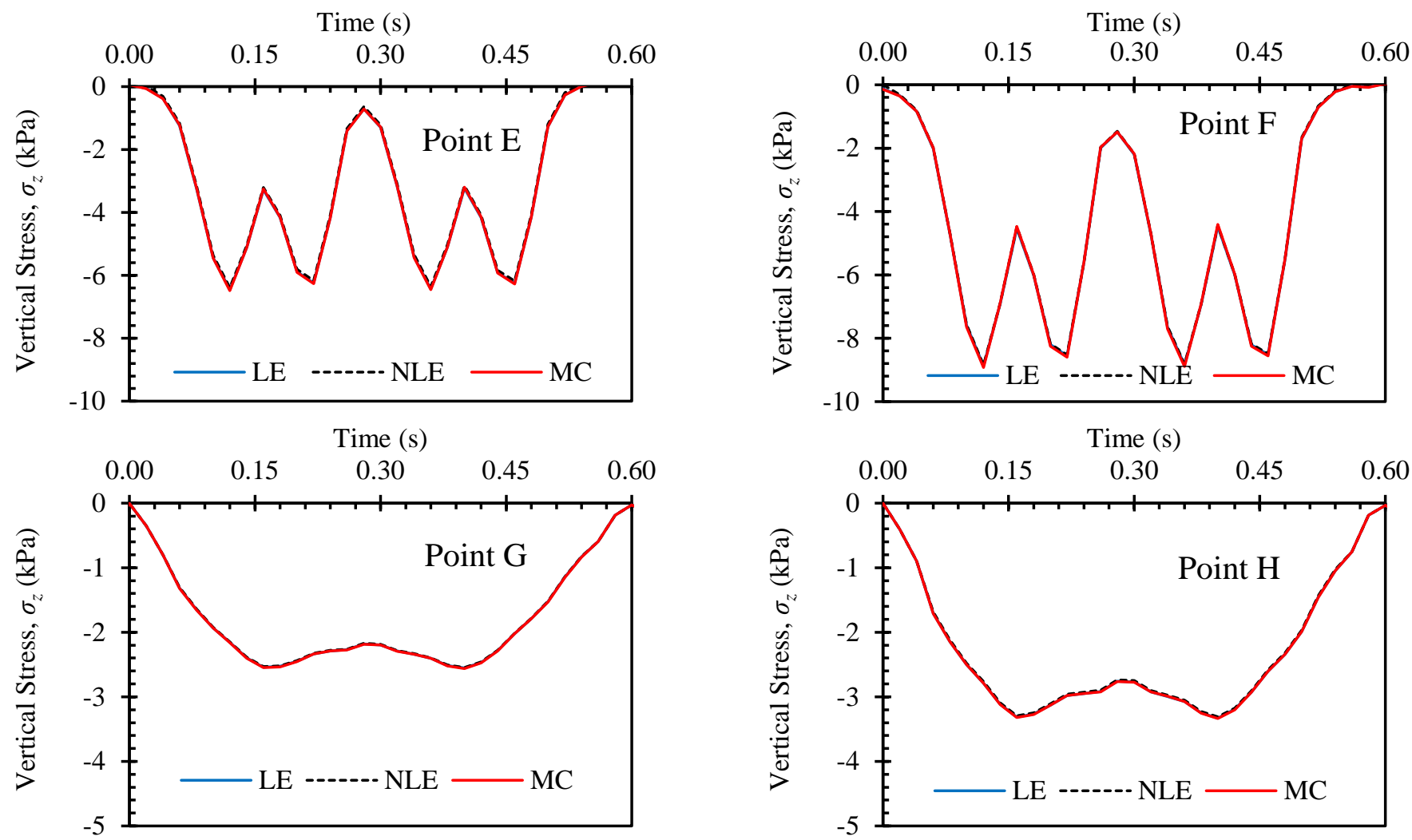

Fig. 9: Time history of vertical stress at Points E to H considering different subgrade constitutive models. 

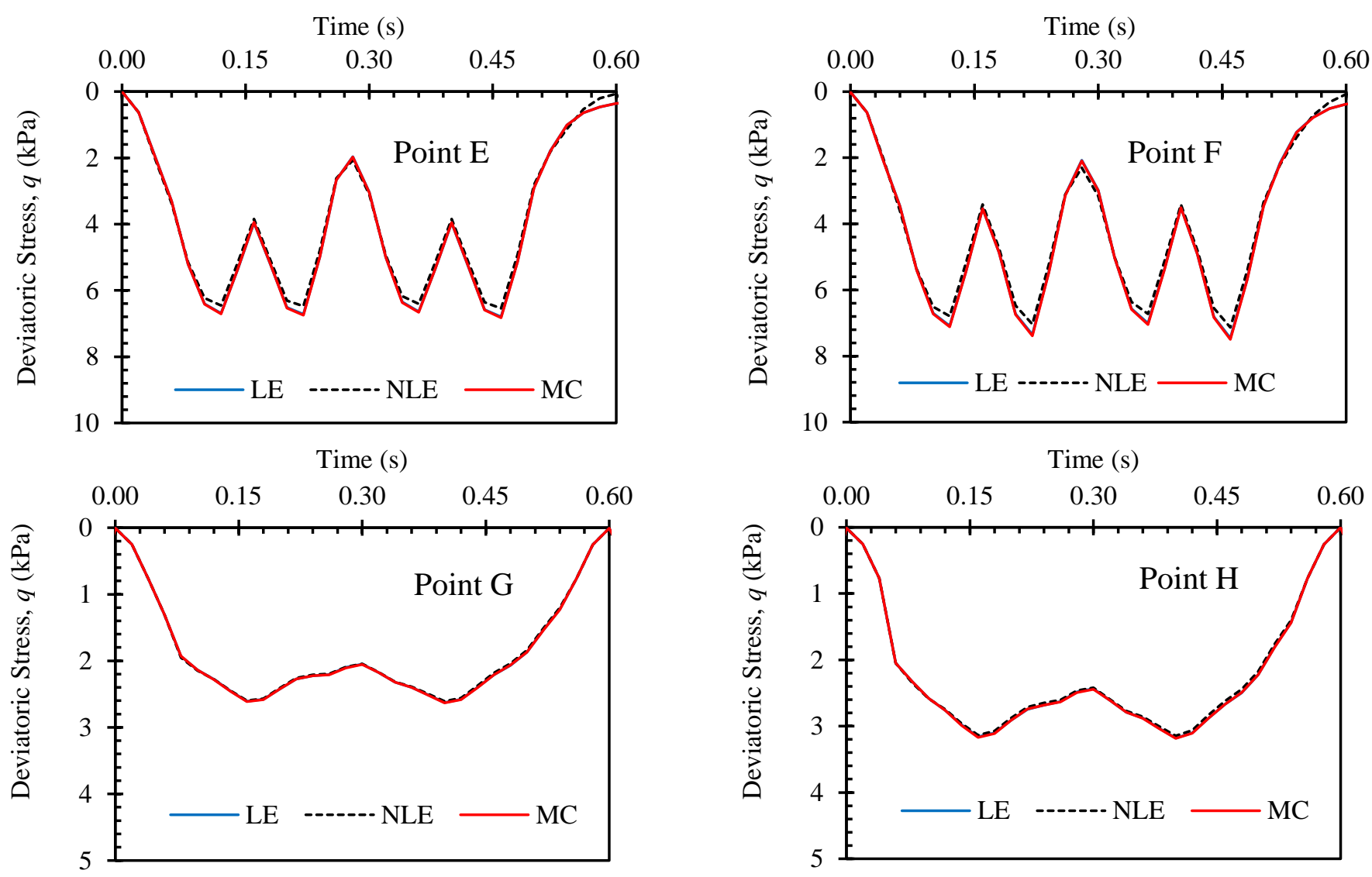

Fig. 10: Time history of deviatoric stress at Points E to H considering different subgrade constitutive models.

These results demonstrate that the linear elastic model underestimates the stresses in the ballast layer; however, it can estimate the stresses in the subgrade soil reasonably well. Nonetheless, the linear elastic model still can be used to estimate the overall track response, as it requires significantly less computational time. For instance, in this study, a computer with processor Intel(R) Core ${ }^{\mathrm{TM}}$ i7-4770 CPU @ $3.40 \mathrm{GHz}$ and $16 \mathrm{~GB}$ RAM was used. The simulation duration for the linear elastic as compared to either the nonlinear elastic or elastoplastic analyses were about 1.5 and 18 hours, respectively.

\section{Summary and Conclusions}

In this paper, an advanced three-dimensional finite element numerical modelling was performed to investigate the impact of some design aspects of ballasted railway track foundations on the track dynamic response subjected to train moving loads. The validity on the simpler linear elastic behavior of track geomaterials for ballast and subgrade were compared to the more realistic nonlinear elastic and elastoplastic models. It was found that the linear elastic model can provide practically good overall track response close to the nonlinear and elastoplastic models. It was also found that Mohr-Coulomb elastoplastic model gives slightly higher stresses in some locations of the ballast layer compared to other models, but similar results for the subgrade layer. However, the linear elastic model required substantially lower computational time, as expected. Based on the results obtained, it is believed that the elastoplastic model of ballast and linear elastic model of subgrade provide reasonable outcomes and can thus be used in design of ballasted railway track foundations.

\section{References}

[1] AREA, "Manual for Railway Engineering," vol 1, American Railway Engineering Association (AREA), Washington, D.C.1996. 
[2] G. P. Raymond, "Design for railroad ballast and subgrade support," Journal of the Geotechnical Engineering Division, vol. 104, pp. 45-60, 1978.

[3] Z. Okabe, "Laboratory investigation of railroad ballasts," Bulletin of the Permanent Way Society of Japan, vol. 4, pp. 1-19 1961.

[4] D. L. Heath, M. J. Shenton, R. W. Sparrow, and J. M. Waters, "Design of conventional rail track foundations," Proceedings of the Institution of Civil Engineers, vol. 51, pp. 251-267, 1972.

[5] UIC, "Earthworks and Trackbed Construction For Railway Lines, UIC Code 719 R, The international Union of Railways, Parish, France," 1994.

[6] D. Li and E. T. Selig, "Method for railroad track foundation design. I: Development," Journal of Geotechnical and Geoenvironmental Engineering, vol. 124, p. 316, 1998.

[7] D. Li and E. T. Selig, "Method for railroad track foundation design. II: Applications," Journal of Geotechnical and Geoenvironmental Engineering, vol. 124, p. 323, 1998.

[8] W. Powrie, L. A. Yang, and C. R. I. Clayton, "Stress changes in the ground below ballasted railway track during train passage," Proceedings of the Institution of Mechanical Engineers. Part F, Journal of rail and rapid transit, vol. 221, pp. 247-261, 2007.

[9] S. F. Brown, "Soil mechanics in pavement engineering," Géotechnique, vol. 46, pp. 383-426, 1996.

[10] A. Inam, T. Ishikawa, and S. Miura, "Effect of principal stress axis rotation on cyclic plastic deformation characteristics of unsaturated base course material," Soils and Foundations, vol. 52, pp. 465-480, 2012.

[11] F. Lekarp, U. Isacsson, and A. Dawson, "State of the art. I: Resilient response of unbound aggregates," Journal of Transportation Engineering, vol. 126, pp. 66-75, 2000.

[12] F. Lekarp, U. Isacsson, and A. R. Dawson, "State of the art. II: Permanent strain response of unbound aggregates," Journal of Transportation Engineering, vol. 126, pp. 76-83, 2000.

[13] B. Indraratna and D. Ionescu, "State of the art large scale testing of ballast," in CORE2000, Railway Technology for the 21st Century, Adelaide, Australia, 2000, pp. 24, 1-13.

[14] M. A. Sayeed and M. A. Shahin, "Investigation into Impact of Train Speed for Behavior of Ballasted Railway Track Foundations," Procedia Engineering, vol. 143, pp. 1152-1159, 2016.

[15] M. A. Sayeed and M. A. Shahin, "Three-dimensional numerical modelling of ballasted railway track foundations for high-speed trains with special reference to critical speed," Transportation Geotechnics, vol. 6, pp. 55-65, 2016.

[16] MIDAS IT. Co. Ltd., "Manual of GTS-NX 2013 v1.2: new experience of geotechnical analysis system," MIDAS Company Limited, South Korea 2013.

[17] V. Galavi and R. B. J. Brinkgreve, "Finite element modelling of geotechnical structures subjected to moving loads," in VIII ECNUMGE - Numerical Methods in Geotechnical Engineering. vol. 1, Hicks et al., Ed., ed Delft, Netherlands: Taylor and Francis - Balkema, 2014, pp. 235-240.

[18] G. Kouroussis, O. Verlinden, and C. Conti, "Finite-dynamic model for infinite media: corrected solution of viscous boundary efficiency," Journal of Engineering Mechanics, vol. 137, pp. 509-511, 2011.

[19] J. Lysmer and R. L. Kuhlemeyer, "Finite dynamic model for infinite media," Journal of the Engineering Mechanics Division, ASCE, vol. 95, pp. 859-877, 1969.

[20] M. A. Sayeed and M. A. Shahin, "Design of ballasted railway track foundations using numerical modelling: Part IDevelopment," Canadian Geotechnical Journal, 2017.

[21] N. M. F. Araújo, "High-speed trains on ballasted railway track: Dynamic stress field analysis," PhD Thesis, Universidade do Minho, Portugal, 2011.

[22] G. Kouroussis, O. Verlinden, and C. Conti, "Ground propagation of vibrations from railway vehicles using a finite/infinite-element model of the soil," Journal of Rail and Rapid Transit, vol. 223, pp. 405-413, 2009.

[23] D. M. Potts and L. Zdravković, Finite element analysis in geotechnical engineering: application. London: Thomas Telford, 2001.

[24] J. M. Duncan, P. Byrne, K. S. Wong, and P. Mabry, "Strength, stress-strain and bulk modulus parameters for finite element analyses of stresses and movements in soil masses," University of California, Berkeley, California Report No. UCB/GT/80-01, 1980. 